\title{
Desenvolvimento infantil e deficiência: notas etnográficas sobre a Síndrome Congênita do Vírus da Zika no Rio Grande do Norte
}

Thais Maria Valim ${ }^{1}$ Universidade Federal do Rio Grande do Norte

Resumo: A noção de "desenvolvimento infantil" estampa todas as cartilhas, manuais e conversas referentes ao acompanhamento de recém-nascidos, bebês na primeira infância e crianças. Há valores referenciais, padrões e metas estipulados a partir de uma universalidade biológica das etapas do desenvolvimento. Neste artigo, procuro refletir sobre como essas normas são negociadas no caso de crianças nascidas com alterações congênitas, como é o caso da Síndrome Congênita do Vírus da Zika, numa tentativa de traçar as diferentes formulações acerca do desenvolvimento observadas durante pesquisa de campo realizada entre famílias implicadas na epidemia do Zika no Rio Grande do Norte.

Palavras-chave: desenvolvimento infantil; deficiência; zika vírus. 


\title{
Child development and disability: ethnographic notes on the Congenital Zika Syndrome in Rio Grande do Norte, Brazil
}

\begin{abstract}
When it comes to caring for children, "child development" becomes a matter discussed on manuals, primers, conversations. There are patterns, goals of development and referential values based on a universal schedule of biological growth. In this article, I try to bring this universality to the ground, in an attempt to trace how different developments, such as that of children born with congenital syndromes, are dealt and negotiated in the lives of children diagnosed with the Congenital Zika Syndrome and their families in Rio Grande do Norte, Brazil.
\end{abstract}

Key-words: child development; disability; zika virus.

\section{Desarollo infantil y discapacidad: notas etnográficas sobre el Síndrome Congénito del Virus del Zika en Rio Grande do Norte, Brasil}

\begin{abstract}
Resumen: La noción de "desarrollo infantil" aparece en todos los folletos, manuales y conversaciones sobre el cuidado de recién nacidos, bebés y niños pequeños. Hay valores de referencia, estándares y objetivos estipulados a partir de una universalidad biológica de las etapas de desarrollo. En este artículo, trato de reflexionar sobre cómo se negocian estas normas en los casos de niños nacidos con alteraciones congénitas, como el Síndrome del Virus del Zika Congénito, en un intento de rastrear las diferentes formulaciones sobre el desarrollo observado durante investigación de campo realizada entre familias implicado en la epidemia de Zika en Rio Grande do Norte, Brasil.
\end{abstract}

Palabras-clave: desarollo infantil; discapacidad; zika virus. 
$\mathrm{D}$ esde 2017, venho pesquisando e conhecendo a realidade de famílias diretamente implicadas na epidemia do Vírus da Zika (ZIKV), arbovírus ${ }^{2}$ que ficou conhecido em todo o Brasil a partir de 2015, ano em que o médico e professor de medicina tropical da UFRN, doutor Kléber Luz, conseguiu identificar o vírus na amostra genética de pacientes que queixavam-se do que até então vinha sendo chamado de "alergia medonha" ou de "dengue-branda" (DINIZ, 2016), devido ao fato de alguns dos sintomas relatados pelos pacientes serem semelhantes aos da dengue, como febre, dores pelo corpo e erupções cutâneas.

Após a identificação e aparente "controle" da situação, no entanto, o Zika voltou a estampar manchetes e reportagens por ser considerado o agente etiológico responsável pelos casos de microcefalia que também passaram a se acumular no país numa proporção nunca antes vista. Adriana Melo, neonatologista de Campina Grande (PB), analisou o líquido amniótico de gestantes cujo ultrassom apontou para microcefalia nos fetos e encontrou traços genéticos do vírus, resultado compatível com o de outras análises e investigações realizadas no país3.

Desde o comunicado oficial do Ministério da Saúde (MS) chancelando a causalidade entre infecção vertical por zika e microcefalia, pronunciado em novembro de 2015 (GONÇALVES, 2015), mais de três mil crianças foram diagnosticadas com o que especialistas passaram a chamar de Síndrome Congênita do Vírus da Zika (SCVZ) ou ainda Síndrome Congênita Associada à Infecção pelo Vírus da Zika (SCAIVZ)4, e, diante desse cenário, muitos projetos de pesquisa foram elaborados em distintas áreas para dar conta de um fenômeno e de uma epidemia dessa monta.

Entre essas iniciativas, localizo o projeto "Zika e microcefalia: Um estudo antropológico sobre os impactos dos diagnósticos e prognósticos das malformações fetais no cotidiano de mulheres e suas famílias no estado de Pernambuco”, a partir do qual tive contato inicial com a epidemia e com a síndrome. A pesquisa, coordenada pela professora Soraya Fleischer (DAN/UnB) 5 , foi pensada a partir de um cronograma de execução que previa o acompanhamento de famílias afetadas por Zika na cidade do Recife ao longo de quatro anos. Como integrante do grupo, tive acesso aos diários de campo previamente editados das colegas que iam à capital pernambucana e construí minha monografia de graduação com base nessas leituras, fazendo, portanto, uma etnografia a partir de dados secundários, ou seja, a partir de dados que não foram por mim produzidos.

Após ter ingressado no PPGAS/UFRN 6 , continuei meus esforços de pesquisa em Natal, sob orientação de Rozeli Porto (DAN/UFRN)7, que também coordena um projeto sobre os desdobramentos da epidemia do vírus da zika e de outras

\footnotetext{
2 Os arbovírus são vírus transmitidos para humanos por meio de artrópodes, como mosquitos.

3 Há uma complexa trama de atores, equipes e investimentos relacionadas às descobertas clínicas e laboratoriais do Zika Vírus. Para uma descrição refinada deste processo, recomendo a leitura do livro Zika: do Sertão nordestino à ameaça global, de Débora de Diniz, citado ao final deste artigo.

4 Embora a microcefalia seja o sintoma clínico mais conhecido, a infecção vertical pelo vírus da zika compreende um grande espectro de manifestações, como alterações cardíacas, oculares, ortopédicas. É devido a essa imensa variabilidade de sintomas que o fenômeno passou a ser compreendido enquanto uma síndrome.

5 Departamento de Antropologia da Universidade de Brasília.

${ }^{6}$ Programa de Pós-Graduação em Antropologia Social da Universidade Federal do Rio Grande do Norte.

7 Departamento de Antropologia da Universidade Federal do Rio Grande do Norte.
} 
arboviroses, chamado Doenças Endêmicas e Saúde: Zika Vírus, dengue, Chikungunya e os Itinerários Terapêuticos de mulheres no Rio Grande do Norte, Brasil. Acompanhada de Fernanda Moura, também orientanda de Porto, frequentei o Centro de Educação e Pesquisa em Saúde Anita Garibaldi (CEPS), localizado no município potiguar de Macaíba, cerca de 25 quilômetros de distância da capital. O CEPS, ou "Anita", como é informalmente chamado, é um dos centros de saúde do $\mathrm{RN}$ que fornece atendimento especializado a pessoas com deficiência e, após a epidemia do ZIKV, foi uma das instituições responsáveis pelo atendimento de crianças diagnosticadas com a SCVZ.

Durante todo esse tempo, além das interações presenciais em campo, procurei acompanhar também grupos de Facebook e páginas no Instagram direcionadas para síndromes raras, crianças com deficiência e "mães especiais". Nessas buscas, encontrei uma página chamada Diagnóstico não é destino, onde as moderadoras procuram reiterar que a deficiência de seus filhos, ou seja, seu diagnóstico, não deve ser entendido como uma condenação, uma sentença, uma tragédia, e sim como uma forma específica de estar e viver no mundo.

A página, embora não tenha pretensões acadêmicas ou científicas, se alinha em muitas das discussões encabeçadas pelos disability studies (estudos da deficiência), área de investigação que procurava estabelecer uma nova perspectiva sobre a deficiência, deslocando-a ou ainda desprendendo-a de compreensões exclusivamente biomédicas, que enquadram a lesão enquanto um desvio da natureza, da norma, da normalidade, sendo, assim, uma desvantagem natural localizada individualmente na vida dos sujeitos (OLIVER, 1996).

Neste artigo, pretendo refletir sobre noção de diagnóstico enquanto destino. Para tanto, divido o texto em três momentos: primeiro, trago uma breve revisão bibliográfica sobre os disability studies, com o intuito de situar melhor a discussão sobre deficiência para as leitoras e leitores; depois, ingressando propriamente na discussão etnográfica, procuro refletir sobre as formas como deficiência e desenvolvimento infantil se conjugam, pensando tanto em narrativas hegemônicas desabonadoras quanto em ressignificações elaboradas pelas famílias.

\section{Estudos sobre deficiência: uma introdução direcionada}

Historicamente marcados como décadas de rebuliço, agitação e organização social em torno de pautas identitárias, os anos 60 e 70 foram palco de inúmeras manifestações e lutas do povo: no movimento negro, no movimento de mulheres, no movimento gay, as ruas se encheram de pessoas que marchavam pelo fim de políticas e práticas opressoras, em especial no norte global ${ }^{8}$. Foi também durante esse período que pessoas com deficiência se organizaram politicamente contra os processos de exclusão e discriminação por elas vivenciados, demandando participação e reconhecimento enquanto sujeitos sociais de plenos direitos.

A academia, embora nem sempre tenha facilidade de estabelecer diálogos com a militância (MACHADO, 2014), foi profundamente impactada pelos movimentos sociais e lutas políticas daquele período, absorvendo - muitas vezes sem o devido reconhecimento - novas gramáticas e significados em torno de questões como corpo, identidade, reconhecimento.

No campo da deficiência, uma organização política em particular teve importantes desdobramentos para os disability studies. Me refiro à UPIAS, Union of

${ }^{8}$ Com a consolidação dos regimes militares na América Latina, marchas e protestos neste período foram muitas vezes violentamente coibidos no continente. 
the Physically Impaired Against Segregation, ou, na tradução de Débora Diniz (2007), Liga dos Lesados Físicos contra a Segregação, consolidada no Reino Unido durante os anos 70 e organizada majoritariamente por sociólogos com deficiência.

A liga tinha como objetivo formar uma organização representativa dos interesses políticos das pessoas com deficiência feita e pensada por pessoas com deficiência, e não somente para elas, caso de todas as instituições voltadas para deficiência até então, como o Royal National Institute of Blind People, fundado em 1868, no Reino Unido, ou o Instituto Nacional de Educação para Surdos no Brasil, fundado em 1857 (DINIZ, 2007). Tais institutos, embora se voltassem para as especificidades de inclusão e educação de pessoas com alguma deficiência, davam continuidade ao modelo médico de deficiência que, para os sociólogos ligados à UPIAS, deveria ser superado ou, no mínimo, repensado.

Segundo este modelo, a deficiência seria um desvio da natureza, uma desordem biológica (BARNES, 2016) alojada em uma pessoa (SIEBERS, 2008), correspondendo, portanto, a questões físicas pertinentes à biomedicina. É um modelo que identifica lesão e deficiência e coloca o corpo lesado como um corpo patológico que deve ser reabilitado ou curado. Como contraponto a essa visão e promovendo uma nova gramática sobre a deficiência, os ativistas e intelectuais da UPIAS lançaram, no ano de 1976, o Fundamental Principles Document, texto que consolidou a organização política e apresentou oficialmente um novo modelo de compreensão da deficiência (OLIVER, 1996: 31).

O modelo social, como foi chamado, vinha para negar a equação de igualdade imediata entre lesão e deficiência, ressaltando que esta última ocorre quando as dinâmicas e estruturas sociais não são adequadas para acolher a diversidade corporal, restringindo, assim, a participação de pessoas com deficiência. O modelo "não nega a especificidade da deficiência, mas a enquadra precisamente na sociedade"9:

\begin{abstract}
Assim, deficiência, de acordo com o modelo social, é tudo aquilo que impõe restrições às pessoas deficientes; desde preconceito individual à discriminação institucional, de prédios públicos sem portais de acessibilidade a sistemas de transporte inutilizáveis; de uma educação segregada a arranjos de trabalho excludentes, e daí por diante. Ademais, as consequências dessas falhas não recaem aleatoriamente sobre os indivíduos, mas são sistematicamente aplicadas sobre pessoas com deficiência enquanto grupo que experiência essas falhas enquanto uma discriminação institucional por toda a sociedade $^{10}$. (OLIVER, 1996: 33, tradução livre)
\end{abstract}

Os pensadores ligados à UPIAS possuíam, em sua maioria, orientações profundamente inspiradas em Marx e em Engels, vislumbrando o modelo social a partir de suas leituras do materialismo-histórico. Assim, a maior demanda do documento lançado em 1976 reivindicava por alteração da estrutura excludente para que a deficiência não fosse vivenciada como opressão (DINIZ, 2007).

Os dois modelos acima apresentados - médico e social - são conhecidos como os modelos clássicos de representação da deficiência (MELLO, 2009) e, embora o modelo social tenha fornecido elementos importantes para um alargamento do modelo médico, que congelava a deficiência em dimensões trágicas/individuais/biológicas, outros aspectos em torno da deficiência foram sendo apon-

\footnotetext{
9 "(...)It does not deny the problem of disability but locates it squarely within society". (OLIVER, 1996: 32)

10 "Hence disability, according to the social model, is all the things that impose restrictions on disabled people; ranging from individual prejudice to institutional discrimination, from inaccessible public buildings to unusable transport systems, from segregated education to excluding work arrangements, and so on. Further, the consequences of this failure do not simply and randomly fall on individuals but systematically upon disabled people as a group who experience this failure as discrimination institutionalised throughout society." (OLIVER, 1996: 33)
} 
tados desde os anos 70: modelo psicológico, modelo caritativo, modelo administrativo. Michael Oliver chega a citar, de forma irônica, que havia mais modelos de deficiência do que modelos na Agência de Modelos de Lucy Clayton (OLIVER, 1996: 31).

Apesar da ironia com relação aos muitos alargamentos e direcionamentos do modelo social inicialmente proposto por Michael Oliver, Paul Hunt, Paul Abberley e Vic Finkelstein no documento de 1976, algumas críticas e ponderações a ele referentes traziam importantes questões que passaram ao largo das preocupações e encaminhamentos da primeira geração de teóricos da deficiência.

O movimento norte-americano Independent Living Movement (ILM), uma das fontes de inspiração para a elaboração do modelo social, postulava e demandava independência para as pessoas com deficiência por meio de alterações estruturais que permitissem, por exemplo, a livre circulação de cadeiras de roda; outro grupo, este de origem sueca, pregava em seu nome a ideia de que as pessoas com deficiência deveriam advogar por si mesmas, ter autonomia em suas decisões (Self-Advocacy Movement). Inicialmente, portanto, os ideais de independência e autonomia atravessaram a luta política da época, pontuada pela noção de que: “1) as desvantagens resultavam mais diretamente das barreiras que das lesões; e 2) retiradas as barreiras, os deficientes seriam independentes" (DINIZ, 2007: 26)

Aqui, é importante ter em mente que os pensadores vinculados à elaboração do modelo social clássico eram, em sua maioria, homens de camadas médias com lesões medulares. Para eles, a retirada de barreiras poderia coincidir com uma vida mais autônoma e independente. Contudo, mulheres, sobretudo mulheres cuidadoras de pessoas com deficiências mais complexas, colocaram luz sobre o fato de que há certas especificidades corporais que demandam assistência e cuidado ao longo de todo uma vida, por mais acessível que se façam os parques, as escolas, as redes de comunicação. A sugestão é de que, ao se afastarem do enclausuramento biológico do modelo médico, os primeiros teóricos da deficiência acabaram recaindo sobre um enclausuramento subjetivo da independência como valor.

Eva Kittay, uma das autoras responsáveis pela crítica feminista sobre o modelo social clássico (KITTAY, 1999), indica que a demanda por independência, presente em basicamente todos os manifestos e documentos iniciais sobre os estudos em deficiência, pode ser relacionada à teoria da justiça ocidental: a independência, ela diz, é divulgada como um valor e um atributo de integridade e dignidade humana; a dependência, do outro lado da relação binária, apareceria então como uma qualidade exclusivamente negativa e indesejável, incompatível com o sujeito soberano ocidental (KITTAY, 2011).

Assim, para Kittay e demais mulheres envolvidas na crítica feminista, como Anne Finger e Adrienne Asch, o modelo social precisava passar por uma revisão que conseguisse abarcar outras experiências de deficiência, dando conta, assim, da subjetividade do corpo deficiente e de processos ligados à dor, ao cuidado, à dependência e a outros elementos que outrora haviam sido descentralizados da discussão por representarem aspectos negativos no imaginário social - que poderiam, segundo os primeiro teóricos da deficiência, perpetuar estereótipos desabonadores.

Acredito, contudo, me alinhando às teóricas feministas da deficiência, que é somente iluminando tais aspectos que podemos imaginar novas representações, mais justas e acolhedoras, de vivências marcadas pela opressão capacitista. Ignorar a diferença, muitas vezes, significa aumentá-la e, por isso mesmo, é preciso 
estar atenta para como os aspectos subjetivos da deficiência estão atrelados também a outros marcadores sociais, como classe, raça, gênero e geração, numa perspectiva atualmente conhecida como interseccional (MELLO e NUERNBERG, 2012).

É, então, a partir da noção de interseccionalidade que procuro pensar, no capítulo que se segue, a interface entre infância e deficiência. Segundo dados da European Disability Forum Issues, Comprehensive Report on Development Cooperation, embora seja difícil mensurar estatisticamente a deficiência à nível global, tendo em vista que as definições e enquadramentos variam muito de país para país, cerca de $78 \%$ a $85 \%$ da incidência de deficiência no mundo refere-se a crianças, concentradas sobretudo no sul global (MELLO, 2009). Essas crianças, em geral, moram em zonas periféricas com parco acesso à educação, à moradia, à alimentação, à água, à segurança e ao lazer, dinâmica que contribui para o que Cláudia Werneck (2004) chama de "ciclo da invisibilidade", noção que ilumina como os silenciamentos subjetivos denunciados pelas teóricas feministas estão presentes no cotidiano de muitas crianças e suas famílias.

A ideia de evidenciar os processos subjetivos relacionados à infância também dialoga criticamente com alguns aspectos semelhantes ao modelo médico, já que a infância foi durante muito tempo compreendida enquanto uma questão de maturação biológica e de pontos universais de desenvolvimento. Pensar na infância como socialmente construída (ARIÈS, 1973; JAMES e PROUT, 1999) permite uma observação mais realista de como as infâncias são diretamente influenciadas pelos marcadores sociais acima citados.

Muito embora tanto a deficiência quanto a infância tenham sido pensadas a partir de novas gramáticas e representações, ambas as categorias são constantemente perpassadas por uma compreensão biologizante, especialmente no caso de crianças com deficiência, cuja rotina se desenrola em muitos aspectos dentro de hospitais e terapias, além de necessitarem, em muitos casos, de fármacos e tecnologias médicas que ampliam a qualidade de vida, elementos que colocam famílias e crianças em contato direto com a biomedicina.

Na próxima sessão, irei orientar as reflexões a partir das experiências etnográficas vivenciadas enquanto acompanhava a rotina de terapias de crianças diagnosticadas com microcefalia no Centro de Pesquisa e Educação em Saúde Anita Garibaldi. Para tanto, tomarei como fio condutor do artigo a noção de desenvolvimento infantil, que aparece como uma importante categoria tanto no discurso médico quanto no discurso das famílias, procurando apresentar etnograficamente os diferentes caminhos e negociações em torno da noção e como essa categoria atravessa as representações acerca da deficiência na infância.

\section{"Essa criança aqui... ela nem mexe": biopolítica, expectativas de desenvolvimento e exigências de normalidade}

Estávamos eu e Fernanda Moura no Centro de Educação e Pesquisa em Saúde Anita Garibaldi. Era a segunda vez que visitávamos o espaço, então ainda não havíamos nos familiarizado com a equipe de terapeutas, com as usuárias e os usuários e com outras funcionárias e funcionários do local. Já estávamos, no entanto, autorizadas por Fabrício ${ }^{11}$, fisioterapeuta responsável pela supervisão de pesquisas e outros estudos realizados no centro de saúde.

${ }^{11}$ Optamos pela utilização de nomes fictícios na escrita deste artigo. 
Assim, com a presença autorizada mas ainda sem ter nossa identidade pessoal negociada e apresentada às pessoas que frequentavam aquele espaço, eu e Fernanda não tínhamos muitas escolhas além de fazer o que antropólogas muitas vezes fazem quando ainda não conhecem ninguém: vagar e perambular com nossos cadernos embaixo do braço, tomando notas sobre o espaço, ainda ocupando uma posição de pessoas-pela-metade, quase-invisíveis, como coloca Clifford Geertz sobre a experiência que teve com Hildred Geertz quando haviam acabado de chegar em uma das aldeias balinesas onde desenvolveram suas pesquisas. Felizmente, eu e Fernanda não nos recuperávamos da malária, como foi o caso de Hildred e de Clifford (GEERTZ, 1973).

Seguimos, então, na nossa condição de "sopro de vento" (GEERTZ, 1973: 186) pelo espaço, registrando onde cada serviço era disponibilizado: havia uma ala específica para a maternidade, uma ala específica para reabilitação de pessoas com deficiência - espaço de interesse maior para nossos objetivos no escopo do que havíamos nos proposto a investigar -, uma outra ala reservada para exames de tomografia, um outro espaço disponível para os muitos estudantes que frequentam o instituto, com mesas de estudo e computadores ${ }^{12}$.

Seguimos para a área externa, onde uma muretinha de mármore fazia as vezes de banco pelas famílias que lá se sentavam enquanto aguardavam por uma consulta, por uma sessão de terapia ou pelo transporte que as levariam para casa. A muretinha estava cheia e, após uma apresentação um pouco tímida, eu e Fernanda começamos a conversar com Leilane, uma mulher alta, negra, com olhos de águia que esperava pelo carro da prefeitura para ir embora. Estava acompanhada de Cauê e Viviane, seus dois filhos. Viviane, de três anos, foi diagnosticada com a síndrome e já havia feito suas terapias do dia: fisioterapia e "terapia da bexiga"13, conforme nos contou a mãe.

A partir desse dia, em que puxamos papo pela primeira vez, estive com Leilane, Viviane e Cauê em muitas situações, já que passei a visitar o centro de saúde ao menos duas vezes por semana. Chegava cedo, antes mesmo dos serviços de terapia, consulta médica e consulta de enfermagem começarem. $\mathrm{O}$ momento de espera era bom para conversar, perguntar, amarrar pontos de histórias que ficaram confusos em outros encontros, como já indicaram outras antropólogas (FLEISCHER, 2018; PORTO, 2014). Foi em uma dessas esperas que Leilane me contou sobre quando recebeu o diagnóstico de Viviane e sobre a experiência traumatizante que viveu durante a avaliação global da caçula:

\begin{abstract}
Eu fui descobrir da microcefalia só depois, né, depois de ter ela. Primeiro, falaram que ela tinha um probleminha, que ia talvez precisar de terapia pra desenvolver $e$ encaminharam a gente pra avaliação global, ai lá, menina, lá que eu ouvi cada coisa, viu? Lá no dia tava a fisioterapeuta e a fono na sala, a fisio mexendo em Viviane, né, aí começou a falar com a fono: 'você tá vendo algum movimento nela? Tá vendo algum movimento nessa menina? Porque eu não tô vendo nada, essa criança é uma criança parada, não vai fazer nada' e a fono concordou, repetiu algumas coisas, $e$ elas falavam assim mesmo sabe como se eu nem lá tivesse...
\end{abstract}

Após essa interação - nada terapêutica, diga-se de passagem -, Leilane con-

\footnotetext{
${ }^{12}$ Conforme o site do Anita: "Localizado em Macaíba, no Rio Grande do Norte, o Centro de Educação e Pesquisa em Saúde Anita Garibaldi está inserido no SUS como serviço de referência ambulatorial para a atenção multidisciplinar à saúde materno-infantil e para reabilitação auditiva, física e intelectual, na proposta de Educação Baseada na Comunidade"(http://www.institutosantosdumont.org.br/unidades/saude-anita-garibaldi/). O CEPS Faz parte da organização Instituto Santos Dumont, idealizada pelo neurocientista Miguel Nicolelis, e que conta, atualmente, com inúmeros projetos reconhecidos a nível internacional.

${ }_{13}$ Trata-se de uma fisioterapia específica para a bexiga neurogênica, condição causada por alterações no sistema nervoso central (SNC) que fazem com que haja retenção de urina, no caso da bexiga hipoativa, ou incontinência urinária, no caso da bexiga hiperativa.
} 
tou que voltou para casa e por lá ficou durante semanas. Não via sentido em entrar na corrida por serviços de saúde e reabilitação se a filha não tinha mesmo nenhuma esperança, como atestaram na avaliação. As palavras, muitas vezes, têm poder performativo e conduzem a atuações. $\mathrm{O}$ reforço discursivo em torno das incapacidades da filha - no diagnóstico, em consultas, nas primeiras avaliações - levou Leilane a acreditar que não havia nada a ser feito. O desalento, que já batia à porta da família desde a demissão de Carlos, marido de Leilane e pai das duas crianças, fez morada naquele núcleo doméstico: todos ainda baqueados com o diagnóstico, com a perda repentina de renda, com as muitas dificuldades que se anunciavam: "Foi um período muito difícil aquele início", relatou Leilane.

A forma negativa utilizada para transmitir tanto o diagnóstico quanto as informações da avaliação global de Viviane se assemelham às narrativas que Gail Landsman, antropóloga e mãe de uma criança com paralisia cerebral, escutou ao longo de sua pesquisa com mães e maternidades associadas à experiência de cuidar de uma pessoa com deficiência (LANDSMAN, 2008).

Assim como no caso de Leilane, as mulheres que participaram da pesquisa de Landsman relataram que, majoritariamente, a notícia da deficiência de seus filhos lhes foi transmitida como uma informação negativa e trágica. Pelo que conta uma das interlocutoras, os profissionais envolvidos no parto de sua filha foram enfáticos em sublinhar as dificuldades, faltas e incompletudes que envolveriam a vida da criança: "No dia em que Kate nasceu, cada pessoa que entrava naquele quarto vinculada ao instituto de saúde só saía depois de ter certeza que eu compreendia a gravidade da deficiência dela" (LANDSMAN, 2008: 91, tradução livre), revelou uma das interlocutoras de Landsman. Faziam questão de enfatizar que a criança jamais poderia levar uma vida independente e autônoma, dado que ilumina o peso valorativo atribuído às noções de produtividade e independência mencionadas pelas teóricas da crítica feminista da deficiência, como comentei na introdução a esta sessão.

Na pesquisa de Landsman, o diagnóstico enquanto experiência negativa e desanimadora relatado pela interlocutora mencionada foi denunciado por quase todas participantes da investigação. De cá, no sul global, pesquisas realizadas a partir do contexto da epidemia do Vírus da Zika também apresentam convergências. A experiência de Leilane se assemelha a histórias que escutamos de inúmeras mães em Natal, no Recife (LIRA, 2017; FLEISCHER, 2018; ALVES e FLEISCHER, 2019), em Salvador (WILLIAMSON, 2018). Histórias que seguiam consistentemente o padrão de sentença sobre a vida, reforçando que as crianças não sobreviveriam ou, caso sobrevivessem, o fariam por pouco tempo e em péssimas condições. Dialogando com as reflexões de LeBreton (2003 [1999]), a anatomia particular da microcefalia à época do surto adquiriu um valor de destino e de destino assombroso ${ }^{14}$.

Para Landsman (2008), a valoração negativa e derrotista depositada sobre recém-nascidos diagnosticados com alguma deficiência - ou até mesmo, como sugere Layne (1996), no caso de bebês prematuros que iniciam a vida em unidades de terapia intensiva neonatais - tem fortes influências de modelos de desenvolvimento infantil pautados exclusivamente em etapas biologicamente programadas de maturação e formação humanas.

Um dos primeiros a esquematizar e consolidar um modelo maturacional infantil foi Arnold Gesell, médico norte-americano que observou centenas de crianças durante a primeira infância em busca de regularidades comportamentais.

14 Vale ressaltar que o Omar Terra, Ministro da Saúde à época do surto, pronunciou-se acerca da epidemia em tom extremamente sensacionalista, referindo-se às crianças nascidas com a SCVZ como uma "geração de sequelados". 
Para o estudo, Gesell, em companhia de Frances Ilg, fundaram, na década de 1920, a Clínica de Desenvolvimento Infantil de Yale, posteriormente transformada no Instituto Gesell de Desenvolvimento Infantil. Naquele espaço, as crianças foram observadas durante as primeiras quatro semanas de vida, passando por testes de reflexo, coordenação, locomoção. Cada etapa gerava uma série fotográfica densa e detalhada que resultou posteriormente no Atlas do Desenvolvimento Infantil: Delineamento Sistemático das Formas e do Surgimento de Padrões Comportamentais Humanos, ilustrado em 3.200 fotografias publicadas em $1934^{15}$, onde Gesell elencava um "inventário de capacidades infantis progressivamente adquiridas e expressas através de movimentos, posturas e gestos significativos" (MENDONÇA, 2010: 323).

Para Gesell, o catálogo fotográfico ${ }^{16}$ de movimentos e habilidades selecionados por ele e por sua equipe eram manifestações de processos internos à composição biológica do ser humano e, por isso, considerados como etapas naturais do desenvolvimento. Embora aspectos externos e ambientais pudessem influenciar nesse processo, Gesell recusava qualquer protagonismo do meio ambiente, atribuindo agência formativa exclusivamente às dinâmicas biológicas (THELEN, 1992).

A teoria maturacional de Gesell foi amplamente aceita e difundida com uma certeza de dimensões quase religiosas (THELEN, 1995). Durante décadas, a escala de Gesell (Gesell Developmental Schedule) foi acionada como referencial para testes e outros instrumentos de aferição da saúde global da criança. Segundo a escala, a criança deveria desenvolver determinadas habilidades de acordo com sua idade cronológica, assim:

De acordo com essa escala, um bebê de 24 semanas deve conseguir se aproximar e
tocar um chocalho com as duas mãos, ao passo que quatro semanas depois a criança
deve conseguir aproximar e tocar um pequeno cubo ou sino com apenas uma mão; no
desenvolvimento motor-grosseiro, na marca de 24 semanas, a criança deve ser capaz
de sentar-se apoiando-se no chão com suas próprias mãos, enquanto que com 28 se-
manas ela já deve conseguir sentar-se de forma ereta por pelo menos um minuto.
(LANDSMAN, 2008: 104, tradução livre) ${ }^{17}$

Tais transformações e marcas da primeira infância são, segundo Gesell e outras teóricas maturacionistas (como Myrtle McGraw ou Mary Shirley), etapas presentes em qualquer processo normal de desenvolvimento e é a partir destes pontos e marcas pré-estipulados que o desenvolvimento de uma criança poderá ser classificado como normal, quando compatível com elas, ou patológico quando com elas não convergir. Assim, crianças com deficiência, como no caso de minhas pequenas interlocutoras e interlocutores, são classificadas, ou melhor, carimbadas pelo rótulo da anormalidade.

O modelo maturacional de Gesell encontrou oposição na teoria do desenvolvimento de Piaget, que concedia às interações da criança com o meio ambiente um protagonismo muito maior do que Gesell propunha em suas pesquisas. Até

\footnotetext{
15 Margareth Mead, antropóloga conhecida por seu trabalho fotográfico entre crianças Balinesas, diz ter se inspirado profundamente na metodologia de Gesell, inclusive teve encontros e conversas com o cientista e publicou um texto sobre suas teorias (MENDONÇA, 2010).

${ }^{16}$ Arnold Gesell foi, em muitos sentidos e como muitos pensadores da época, fortemente influenciado por Charles Darwin, não só pela identificação de regras naturais da evolução, como também por sua metodologia. O próprio Darwin foi um atento observador da infância, guardando registros e notas sobre os filhos, além de utilizar-se amplamente da fotografia como método de análise: "I found photographs made by the instantaneous process the best means of observation, as allowing more deliberation”, disse o biólogo, como relata Gesell (DARWIN apud GESELL, 1939).

${ }_{17}$ "According to this scale, for instance, an infant of 24 weeks should approach and grasp a rattle with two hands, while four weeks later the child should approach and grasp a small cube or bell with only one hand; in gross motor development at 24 weeks, the child should be able to sit well leaning on his or her hands, while at 28 weeks he or she should sit erect for about one minute." (LANDSMAN, 2008: 104)
} 
hoje, ambos os teóricos são frequentemente acionados nas discussões sobre estágios do desenvolvimento infantil e, embora partam de premissas distintas, se assemelham na noção de que existe uma trajetória universalmente esperada a ser traçada pelo recém-nascido ao longo de sua infância. Os dois mais conhecidos teóricos na área, portanto, sugerem estágios cronológicos de desenvolvimento normal e esperado, ponto que repercute nas representações acerca da infância das mais diversas maneiras e tem influências sobre diferentes atores sociais, desde médicos, psicólogos e fisioterapeutas até mães e pais em seus cotidianos.

Há, resguardada sobre tais premissas, uma expectativa de desenvolvimento que é a todo momento verificada, fiscalizada e avaliada, mesmo que de forma não intencional. Recorrendo a Schutz (1962), nosso estoque simbólico, ou seja, nosso arsenal de significados e formas de dar sentido ao mundo, influi diretamente em nossa conduta social e é arranjado de maneira que construímos expectativas e muitas vezes certezas sobre a realidade na qual estamos atuando.

Esse estoque, cumulativo, é construído a partir de nossas experiências pretéritas: por meio do que e como aprendemos, tipificamos os acontecimentos em esperados ou não esperados, possíveis ou fantasiosos. Um modelo hegemônico como no caso das teorias supracitadas - tem forte peso sobre essas expectativas, não só durante o anúncio de um diagnóstico, por exemplo, mas também em momentos triviais do dia a dia. A ideia é a de que alguns elementos são transformados em "expectativas normativas e em exigências" (GOFFMAN, 2004:5) em nossas interações com o mundo, em nossas noções de realidade.

Voltemos ao diálogo com minhas interlocutoras, para ilustrar um pouco melhor o assunto. Lúcia é outra mulher que conhecemos por meio da pesquisa. Como Leilane, ela vai duas vezes por semana ao "Anita" com o filho José Luiz, que completará 4 anos em dezembro de 2019. Estávamos sentadas na famosa muretinha do instituto, já citada neste artigo, aguardando pela consulta do urologista de José, que, como Viviane, também possui bexiga neurogênica.

Conversávamos sobre a vaquejada que aconteceria em sua cidade na semana seguinte, quando uma mulher se aproximou de nós duas e nos cumprimentou. Ela também aguardava, mas, ao contrário de Lúcia, sua espera não era mais pela consulta e sim pelo carro da prefeitura que a levaria para casa. Após nos cumprimentar, direcionou o corpo e a voz a José, que estava no colo de Lúcia: "Oi, bebê. Boa tarde. Como você é lindo". Ela falava, com entonação doce e infantil. "Ele já tem o que, hein? Um ano e meio, dois anos?", perguntou, dessa vez direcionando a voz a Lúcia.

Alguns segundos de silêncio se sucederam enquanto Lúcia ajeitava José no colo, um pouco cabisbaixa: "Não, não, ele tem quatro já. É que ele é especial". A mulher ruborizou-se, mas nada disse além de reiterar o comentário sobre a fofura de José. As expectativas dela, ao que me parece, estavam atravessadas pelo modelo linear e universal de desenvolvimento, segundo o qual uma criança de quatro anos é reconhecida pela habilidade de sentar-se, sustentar o pescoço, ficar em pé. Ao ver José no colo da mãe, de tempos em tempos chorando um chorinho fino, acionou o estoque simbólico de habilidades e usos do corpo atribuído aos bebês, levando a especulação sobre a idade máxima de dois anos atribuída a José. Vi cenas parecidas acontecerem pelo menos mais duas vezes com Lúcia e José. Nelas, o garoto era sempre identificado como um bebê muito novo e, em todas as vezes, tinha a sensação de que Lúcia não ficava plenamente a vontade durante essas interações.

Não posso aqui garantir certezas sobre os motivos do incômodo de Lúcia, mas posso abrir espaço para algumas especulações. O constrangimento que observei 
em Lúcia, não só nas cenas descritas acima, mas também em conversas sobre o desenvolvimento de outras crianças, sobre marcas e conquistas, pode ser vinculado à ideia de que o desenvolvimento normal, ou melhor, a "normalidade" é, diante da biopolítica atual, um valor. Vivemos em um mundo de normas e como coloca Davis: "provavelmente, não há nenhuma área da vida contemporânea em que algum tipo de norma ou de média não tenha sido calculada"18 (DAVIS, 1995: 23, tradução livre).

Assim, seguindo a estrutura binária do pensamento hegemônico ocidental, se o normal é positivo, bom e justo, o anormal, seu par binário, recebe qualidades negativas: ruim, indesejável, intolerável. A construção histórica da normalidade como valor remete, também, aos mecanismos do processo civilizador (ELIAS, 1994), que se utilizou de uma distribuição valorativa das diferenças para, por um lado, estipular um padrão a ser seguido pela população e, por outro, vigiar e manter à margem aqueles que não o alcançavam. É criado, de certa forma, um desejo pelo padrão e uma aversão pelo desvio.

Essa distribuição valorativa das diferenças é bem descrita por Landsman em seu trabalho com mulheres mães de crianças com deficientes. A autora traz inúmeros relatos sobre o comportamento e reação das pessoas antes e depois de um diagnóstico de deficiência, por exemplo: "Quando ela nasceu e as pessoas ouviam que havia algo errado, foi tipo, os desejos de parabéns e as felicitações desapareceram, era como se você sequer tivesse um bebê ${ }^{19}$ ", disse Lilly Beckett, uma das interlocutoras do trabalho em questão (2008: 57).

Fazendo um retorno a Goffman (2004), a fuga do que se exige pelas expectativas nunca é simples, ela envolve uma cobrança ou fiscalização sobre cada milímetro que se desloca da régua das expectativas sociais. O que Goffman chama de identidade social virtual está relacionada a expectativas com relação à normalidade, mas também dialoga com as expectativas em cima da anormalidade: há certas expectativas sobre o que uma pessoa com deficiência, por exemplo, pode ou não pode fazer e, muitas vezes, esse conjunto de expectativas é envolvido por um manto de desvalorização e desqualificação das possibilidades de vida de pessoas com deficiência.

O discurso negativo sobre a deficiência nas sociedades ocidentais é tão naturalizado que Gail Chödrön (2015: 12), acionando Campbell, coloca a questão como uma ontologia negativa associada a deficiência: "a ideia de que a deficiência tem uma ontologia negativa significa que corpos deficientes são vistos como inerentemente indesejáveis e intoleráveis ${ }^{20}$ " (tradução livre), como se a desvantagem de pessoas com deficiência fosse algo absoluto, essencial, natural. A filósofa, que também é mãe de uma pequena garota com deficiência, pontua que, na produção/manutenção dessa ontologia, aspectos negativos da deficiência são constantemente reforçados nas mais diferentes esferas e nas práticas do dia a dia: nos modelos hegemônicos de desenvolvimento, com aferições e medidas averiguando irregularidades e diagnosticando anormalidades; na ausência de pessoas com deficiência representadas na mídia, nas artes, nas narrativas; até mesmo em uma antipropaganda do governo do Canadá, que aponta os riscos do tabagismo estampando, nas embalagens de cigarro, imagens de um homem que passou a ser cadeirante após um infarto.

\footnotetext{
18 "There is probably no area of contemporary life in which some idea of a norm or average has not been calculated" (Davis, 1995: 23).

19 "When she was born and people heard there was something wrong, like, the congratulations disappears, it's like you don't even have a baby" (Landsman, 2008:57).

20 "The idea that disability has a negative ontology means that disabled bodies are viewed as inherently undesirable and intolerable" (Chodron, 2015:12).
} 
Para Chödrön, tal manutenção da deficiência enquanto algo de menor valor pode ser melhor compreendida a partir de um diálogo com Foucault, para quem o poder - ou as relações de poder -, nas sociedades contemporâneas, é exercido sobre a vida a partir da produção de conhecimento e verdades autoritárias sobre os corpos (CHÖDRÖN, 2015). A associação da deficiência a um atraso no desenvolvimento é uma associação que se ancora, entre outros elementos, na força de verdade com que questões associadas à natureza foram historicamente produzidas pela epistemologia ocidental.

Como bem pontua Isabelle Stengers, as ciências "duras" e "naturais" se apresentam como conhecimentos objetivos sobre a realidade, libertas das comuns "ficções humanas" de outras ciências. O manto de realismo que envolve a física, a matemática e a própria biomedicina faz com que qualquer ponderação e reflexão crítica sobre o fazer científico nessas áreas - e, consequentemente, sobre as verdades que produzem - soe como um ataque à própria racionalidade (STENGERS, 2005).

É com relação a esse discurso da verdade que corpos dissidentes são avaliados, medidos, esquadrinhados: são considerados desvios da ordem natural das coisas. E por isso devem ser curados, reabilitados, redimensionados, normalizados. É sob a justificativa da ciência e da saúde, da materialidade dos corpos, que se ancoram as exigências e padrões elaborados. E aqui também podemos compreender melhor a noção da normalidade enquanto valor, que mencionei enquanto descrevia as reações de Lúcia sobre as avaliações alheias sobre seu filho: ela está associada a essa verdade construída sobre o que se espera de um ser humano.

Essa verdade autoritária sobre o que é o humano e sobre a normalidade enquanto valor produz reações muito violentas sobre o diferente. Em nossa experiência de pesquisa, por exemplo, ouvimos relatos ao longo de todos esses anos após o surto de pessoas desconhecidas que se dirigiam aos bebês e às crianças chamando-os de "demônios", de "monstros", "ETs" e outras criaturas localizadas fora da esfera da humanidade. Todos esses termos remetem à negação do status de sujeito e de humano dessas crianças.

Os monstros, nomenclatura muito utilizada para ofender as crianças e famílias que conhecemos, por exemplo, são historicamente identificados com a deformidade, com a incompletude, com o desvio. Jorge Leite Jr. ilustra isso recuperando a definição de monstro proposta por Ambroise Paré, um médico francês, em 1573: "os monstros são as coisas que aparecem contra o curso da natureza" (LEITE Jr., 2006: 8). Foucault, ao tratar sobre o tema, também apresenta a ideia de transgressão das leis naturais na definição de monstro e demonstra como essa transgressão vem associada, também, a uma punição, como, por exemplo, a exclusão dos corpos abjetos e monstruosos dos espaços públicos e da vida social (2001). Inclusive, muitas pessoas, além de descreverem as crianças que conhecemos na pesquisa como monstruosas, muitas vezes recusam-se a chegar perto delas para dar um "xêro" ou até mesmo a sentarem-se ao seu lado em ônibus e metrôs.

A própria existência dos corpos dissidentes seria, assim, uma afronta à verdade da natureza, à ordem, à harmonia, ao padrão de civilidade. A deficiência e os desenvolvimentos infantis considerados atípicos são, dentro dessa perspectiva, atentados à ordem esperada do mundo. Embora, constitucionalmente, a dignidade de todas as pessoas deva ser garantida, os movimentos políticos e históricos localizam e avaliam os corpos de maneiras distintas. É como se o status ontológico dessas pessoas enquanto sujeitos plenos - enquanto pessoas, afinal - não 
fosse estável.

No que concerne aos bebês, por exemplo, Landsman relembra que "na literatura em bioética, recém-nascidos, apesar de humanos, são compreendidos enquanto seres que não apresentam certas características atribuídas às pessoas, como capacidades cognitivas e a habilidade para deliberar racionalmente" (LANDSMAN, 2008: 56, tradução livre). Há uma seleção de características exigidas para preencher as normas de pessoalidade, e, entre elas, podemos elencar a aparência física e um determinado roteiro de desenvolvimento.

Quando não preenchidas, essas exigências repercutem na exclusão, na estranheza. Na realidade, qualquer fuga às exigências é penalizada, em nuances que vão desde um simples desconforto até o extermínio, a depender da posição do sujeito com relação à norma. Vale reforçar o que disse na metodologia: majoritariamente, as pessoas implicadas na epidemia do vírus da zika são mulheres negras moradoras da periferia, em sua maioria nordestinas, mães de crianças também negras, nordestinas, moradoras da periferia e com deficiência.

São pessoas, portanto, que não passaram a vivenciar a exclusão a partir da opressão à deficiência e, sim, convivem com a marginalização de seus corpos e a negação de suas subjetividades há longos ciclos. A "normalidade", nesse contexto, é mais um elemento de distinção que se mostra inalcançável. Há, no fenômeno dessa epidemia, muitas camadas de desigualdade se perpetuando (DINIZ, 2016; MELLO e NUERNBERG, 2012) e elementos aparentemente naturais como o "desenvolvimento infantil" também vêm embebidos em concepções essencialistas que atualizam essas diferenciações.

Contudo, embora modelos hegemônicos tenham força e se atualizem por meio de políticas públicas, de propagandas e de produtos de consumo, nada no mundo é formado e moldado por uma única fonte. Como sugere Moser (2000), não somos constituídos por uma única forma hegemônica de discurso: nas práticas do cotidiano, outras narrativas e discursos vêm à baila, ora corroborando o discurso hegemônico, mas também negociando-o e tensionando-o. Na próxima seção, procuro refletir sobre outras narrativas de desenvolvimento construídas no cotidiano do cuidado das famílias que acompanhei na pesquisa.

\section{Desenvolvimentos múltiplos: ontologias em disputa, mundos em elaboração}

Após passar cerca de um mês em casa, saindo somente para realizar atividades inevitáveis, Leilane foi procurada por uma assistente social vinculada à prefeitura de São Gonçalo do Amarante, município do Rio Grande do Norte onde mora a família. A profissional queria saber sobre a rotina de Viviane: como a criança estava, se frequentava terapias, se estava tomando alguma medicação. Leilane, ainda traumatizada com a última experiência, respondeu que nas consultas ainda não haviam indicado nenhum remédio para a filha e que, com relação às terapias, Viviane não ia em nenhuma e seguiu descrevendo para a assistente social como as duas haviam sido tratadas durante a avaliação global de sua caçula.

"Isso é um absurdo", respondeu Lia, a assistente social em questão. "Como podem falar com uma mãe dessa maneira? Isso não se faz". Lia sugeriu, então, que Leilane desse mais uma chance às terapias, que ela mandaria um carro da prefeitura buscar as duas, bem na porta de casa, e as deixaria em frente ao centro de saúde. Leilane estava tão baqueada que respondeu: “Eu agradeço e a senhora pode mandar, mas eu não vou". No dia combinado, no entanto, o carro apareceu e Leilane decidiu levar a filha mais uma vez para uma avaliação: 
Nesse dia o tratamento foi diferente, sabe? As fisioterapeutas falaram para eu esquecer os absurdos que as outras médicas disseram. Que era importante que Viviane fosse às terapias, que resultado a gente sempre vê, me animaram com relação ao futuro, falaram de outras crianças que estão evoluindo muito na fisioterapia, no seu ritmo.

O encontro inaugurou uma nova fase na vida da família. Viviane passou a fazer fisioterapia, fonoaudiologia, terapia ocupacional, terapias voltadas para a bexiga neurogênica. Na vivência das terapias, a ideia de desenvolvimento e de evolução são categorias presentes constantemente, mas não de forma homogênea. Embora, no conjunto terapêutico, a ideia hegemônica da normalização apareça também com uma certa constância, ela se mescla, se encontra e se confronta com outras formas de narrar a deficiência, outras maneiras de lidar com a diferença corporal. No Anita, instituição onde Viviane faz a maior parte de suas terapias, por exemplo, a proposta é a de nunca trabalhar com a noção de normalidade/patologia, respeitando sempre as individualidades, reconhecendo as especificidades: "a gente precisa adaptar a terapia à criança e não só a criança à terapia”, me disse uma das profissionais da instituição.

Nas sessões de fisioterapia, fonoaudiologia, consultas com urologistas e neurologistas que pude acompanhar enquanto visitante no Anita, observei que aquela era uma preocupação de muitos profissionais. Todas as avaliações eram conduzidas a partir da trajetória de cada criança, nunca de comparações entre uma e outra. Cada profissional conhecia muito bem seus pacientes e estavam familiarizados não somente com os aspectos técnicos de cada prontuário, mas sabiam quais músicas cada uma das crianças gostava, conseguiam manter um bom acompanhamento de suas rotinas fora do instituto. Em uma das sessões em que estava acompanhando Lúcia e José Luiz, vi Paloma, fisioterapeuta, distinguir pelo menos três tipos de convulsões do menino:

\begin{abstract}
Ele agora tremeu a perninha, você viu? Tem crise que ele treme os membros inferiores, tem crise que já pega nos superiores, em outras ele fica completamente imóvel e toda a movimentação se dá nos olhos. Eu já aprendi a ver, já aprendi a reparar. Quando ele volta da crise, passa um tempo aéreo, vai voltando aos poucos e eu preciso adaptar a terapia a ele, preciso conhecer ele.
\end{abstract}

A partir desse conhecimento íntimo da criança, que os profissionais de saúde em questão detêm e no qual as mães são praticamente especialistas, uma série de diferenciações, transformações e agitações de desenvolvimento vão sendo notadas. No lugar de utilizarem a escala de desenvolvimento padrão, diante da qual as crianças com deficiência são, como vimos, desvalorizadas, uma escala individual é construída para cada criança (WILLIAMSON, 2018; VALIM, 2019), capaz de captar, identificar e nomear os vários desenvolvimentos em jogo.

Em uma outra manhã, em que acompanhei José e sua família, por exemplo, estávamos em uma sessão de fonoaudiologia. Lúcia estava sentada em uma banqueta com José no seu colo, posicionado de frente para Marília, a fono, que preparava um material que seria inserido na boca de José para estimular certas sensações no menino: primeiro, uma espátula encoberta por uma camada de algodão molhado com água quente; depois o mesmo material encoberto com água fria. Marília ia conduzindo a espátula dentro da boca de José, mexendo para frente e para trás, em seguida mudando a posição do material para a lateral da língua, onde o movimento de vai e vem se repetia.

A cada etapa, Marília ia ensinando a José: “Esse aqui é quente, José”, repetia, deslizando a espátula delicadamente para dentro e para fora da boca do garoto. Lúcia, então, comentou: "Eu notei que ele começou a reclamar, sabe, do gosto do 
remédio, do barbital ${ }^{21}$, ele resmunga agora, tipo como quem acha ruim, e antes ele não resmungava”. Marília retirou a espátula com algodão quente da boca de José e completou: "É que ele tá aprendendo, mãe, que as coisas têm gosto, que as coisas têm temperatura, têm textura".

Aquela era uma conquista, uma evolução a ser comemorada da mesma forma que os primeiros passos de uma criança com desenvolvimento considerado típico o são. Em ambas as situações, as crianças estão, na realidade, realizando algo tipicamente humano: o aprender. Contudo, seguindo os modelos de desenvolvimento biologizantes, tudo se passa como se a criança com desenvolvimento considerado típico adquirisse naturalmente essas habilidades, ao passo que José Luiz, por exemplo, precisasse ser ensinado. E isso, como vimos acima, entra no conjunto de aspectos negativos associados à deficiência.

A ideia de que há um conjunto de habilidades e competências inatas ressoa a discussão sobre o inato versus o adquirido, tema que perpassa a antropologia desde suas fundações (KRÖEBER, 1933). A investigação antropológica, inclusive, iluminou como certas características transmitidas e ensinadas são naturalizadas de forma tão intensa que passam a impressão ilusória de que se tratam de dados objetivos do mundo natural, mascarando a sua construção histórica num processo que, recorrendo a Bourdieu, podemos chamar "amnésia da gênese" (BOURDIEU, 1983: 66).

Marcel Mauss, em As técnicas corporais, um famoso e agradável texto, traz uma série de exemplos das técnicas e aprendizagens envolvidas em certos usos do corpo que, à primeira vista, soam como atributos inquestionavelmente naturais, como, por exemplo, o andar, que parece refletir um processo de desenvolvimento anatômico absolutamente natural na vida. Contudo, Mauss, ao apresentar diferentes tipos de marcha, ritmos de caminhada e estilos de pisada, revela como o andar está imerso em intensos processos de aprendizado de técnicas: o andar não é absoluto, invariável e, sim, localizado, múltiplo. Em certa medida, todos aprendemos e somos ensinados a usar o nosso corpo, sendo ele nosso primeiro instrumento (MAUSS, 2003).

As crianças com deficiência estão, da mesma forma que as crianças com desenvolvimento considerado típico, apresentando diferentes formas de evoluir, de aprender, de conhecer e explorar o corpo. Para pensar o corpo com deficiência enquanto mais uma forma de estar no mundo dentre outras, e não como uma anormalidade/desvio/patologia, é preciso se afastar de modelos fixos, rígidos e que funcionam muitas vezes como asfixiantes espartilhos da vida.

Há toda uma nova gramática do desenvolvimento sendo formulada pelas mães e demais cuidadoras, que conhecemos no âmbito da pesquisa, que possibilitam novas representações acerca da deficiência e da infância: as famílias celebram a diferença de seus filhos, enfatizam o quanto aquelas crianças lhes ensinam sobre o mundo, sobre a vida. Descobrem juntos novas possibilidades, resistem juntos às opressões normalizadoras. Reterritorializam o campo semântico outrora imposto, renovam e ampliam fronteiras, ampliam conjuntos de técnicas e conhecimentos.

O que na gramática hegemônica é considerado desvio é revisto como potência, como uma incrível força presente nessas crianças que, a despeito das avaliações negativas e da descrença generalizada, seguem vivendo e nesse viver transformam relações sociais e recriam expectativas. Talvez por isso incomodem tanto: seus corpos dissidentes são lembretes constantes de que há outros mundos, há

${ }^{21}$ Abreviação do Fenobarbital, medicamento utilizado no arranjo de remédios para controlar as crises convulsivas do menino. 
outras possibilidades para além da normopatia excludente, de que a realidade não é absoluta, única, estável.

Contudo, não é possível ignorar a existência de narrativas redutoras, afinal, elas também estão implicadas em uma série de práticas do dia a dia. O modelo hegemônico, embora seja contestado, negociado e remanejado pelas famílias, continua tendo fortes efeitos sobre a vida cotidiana. Durante uma conversa que tive com Tâmara - interlocutora que conheci durante uma viagem para Fortaleza, onde seu filho, Marquinhos, participaria de uma competição de paratletismo infantil na modalidade de natação -, ela me disse: "Todo dia você tem que se reconstruir, quando chega no final do dia e você pensa em todas as cenas que aconteceram... e precisa se reerguer, se rearranjar pra começar tudo de novo no dia seguinte".

Naquele momento, falávamos sobre as muitas experiências de exclusão vivenciadas por ela e pelo filho. Mais cedo, tentando nos deslocar até o Clube Náutico Atlético Cearense, complexo esportivo onde as competições estavam acontecendo, eu, Viviane, Tâmara, Leilane e Marquinhos passamos por situações embaraçosas e humilhantes com dois motoristas de Uber que cancelaram a viagem quando viram que se tratavam de crianças com deficiência. Mais tarde, a mesma situação aconteceria na viagem de volta: "Tá vendo como não tem espaço no mundo?", Tâmara me reforçava.

As palavras de minha interlocutora me fizeram lembrar de Raynna Rapp e Faye Ginsburg (2001), que discorrem sobre como a deficiência é, em muitas sociedades ocidentais, alojada na esfera do extraordinário, distante das coisas e relações do mundo cotidiano. No entanto, elas sugerem, isso é uma falácia, já que a deficiência está constantemente presente, mas é também constantemente silenciada, invisibilizada, confinada. Como propõe o modelo social da deficiência, apresentado na introdução deste artigo, o que definirá a forma como a pessoa com deficiência participa ou não da sociedade não está localizado exclusivamente em dados naturais ou biológicos e, sim, na forma como a própria sociedade recebe a diferença.

Entre os Karitiana, povo indígena de língua tupi-arikém da Amazônia Meridional, por exemplo, pessoas com deficiência, chamadas de osikirip, demonstram, em alguns casos, dificuldades em realizar atividades consideradas essenciais para a manutenção da vida, como varrer a casa e lavar louça no rio, no caso de mulheres e crianças, e de caçar, no caso dos homens. Mesmo assim, os Karitiana não deixam de reconhecer tais pessoas como seus parentes, como humanas e, por isso, se engajam na construção de socialidade com elas. Como indica Íris Araújo (2015: 52), "todos contribuem para isso: uma mãe me explicou que aos pais das crianças não especiais cabe a tarefa de ensinar aos filhos o cuidado e a paciência que se deve ter com aqueles que são especiais”. Assim, ainda que a diferença entre os osikirip e as pessoas consideradas normais seja demarcada, essa diferença não os exclui e nem os marginaliza, como aconteceu com Marquinhos e Viviane na cena do Uber ou como na própria narrativa desenvolvimentista que identifica a diferença como atraso ou falha.

Nesse sentido, as narrativas alternativas de desenvolvimento elaboradas pelas famílias que conheci operam também como um instrumento de inclusão, de construção da socialidade e funcionam também como uma demanda pela possibilidade de existência, por participação e "espaço no mundo", afinal. A disputa por outras leituras da deficiência e do desenvolvimento é uma disputa também ontológica, onde se discute quem e o que é valorizado. Uma ontologia, como coloca Annemarie Mol (2008: 68-73), "define o que pertence ao real” e coloca as 
"condições de possibilidade" com que vivemos. A realidade, sugere Mol, não é fixa, estável e absoluta, como queriam as ciências "duras", e sim localizada histórica, cultural e materialmente. Assim, há tantas ontologias quanto há realidades. O desenvolvimento e a deficiência, questões aqui tratadas, não são fixos e imutáveis. Tratam-se, também, de inúmeras versões que são construídas e elaboradas diariamente a partir da vida e das interações práticas.

Nesta leitura, a deficiência, por exemplo, não é algo que possa ser definido com exatidão e exclusividade: sua realidade irá depender das diferentes articulações que a colocam em prática, podendo resultar em práticas excludentes ou, por outro lado, inclusivas. A deficiência entre os karitiana é distinta da deficiência diagnosticada por um técnico de ultrassom em uma capital brasileira, bem como há diferentes versões do que é deficiência se perguntarmos a um adepto do desenvolvimentismo infantil ou a uma amorosa mãe que cuida de sua filha com microcefalia. Todas essas respostas são reais e são elaboradas nas práticas, interações e articulações do cotidiano.

As diferentes práticas resultam, efetivamente, em diferentes realidades, em diferentes experiências de deficiência. Assim, as práticas de ressignificação do desenvolvimento das crianças elaboradas pelas famílias que conheci, resultam, ainda que de forma não hegemônica, em diferentes ontologias, em diferentes produções do real que permitem outras possibilidades de vida para crianças com deficiência. Ao denunciarem que não há "espaço no mundo" para seus filhos, como me disse Tâmara, as mulheres que conheci estão também, afinal, propondo e criando outros mundos.

Recebido em 31 de agosto de 2019.

Aprovado em 24 de novembro de 2019.

\section{Referências}

ALVES, Raquel; FLEISCHER, Soraya. 'O que adianta conhecer muita gente e no fim das contas estar sempre só?’ Desafios da maternidade em tempos de Síndrome Congênita do Zika Vírus. Revista Anthropológicas, 29 (2): 6-27, 2018.

ARAUJO, Iris Morais. Osikirip: os 'especiais' Karitiana e a noção de pessoa ameríndia. Tese (Doutorado em Antropologia Social), Faculdade de Filosofia, Letras e Ciências Humanas, Universidade de São Paulo, São Paulo, 2015.

ARIÈS, Philippe. História Social da Criança e da Família. 2. ed. Rio de Janeiro: LTC, 1981.

BARNES, Elizabeth. The Minority Body: A Theory of Disability. Oxford: Oxford University Press, 2016.

BOURDIEU, Pierre. "Esboço de uma teoria geral da prática”. In: BOURDIEU: sociologia. São Paulo: Ática, 1983. pp. 82-122

CHÖDRÖN, Gail. Inclusion without Potential: Disability and the Biopolitics of Neuro-logical Human Capital Investments. ProQuest Dissertations and Theses, 2015. 
DAVIS, Lennard. Enforcing Normalcy: Disability, Deafness and the Body. New York: Verso, 1995.

DINIZ, Débora. Zika: Do sertão nordestino à ameaça global. Rio de Janeiro: Civilização Brasileira, 2016.

DINIZ, Débora. O que é deficiência. São Paulo: Editora Brasiliense, 2007.

ELIAS, Norbert. O Processo Civilizador. Vol.1: Uma História dos Costumes. Rio de Janeiro: Jorge Zahar, 1994.

FLEISCHER, Soraya. Segurar, caminhar e falar: notas etnográficas sobre a experiência de uma "mãe de micro" no Recife/PE. Cadernos de Gênero e Diversidade, 3 (2): 93-112, 2017.

FLEISCHER, Soraya. Descontrolada: Uma Etnografia dos Problemas de Pressão. Brasília: EdUFSCar, 2018.

FOUCAULT, Michel. Vigiar e punir: nascimento da prisão. Tradução de Lígia M. Pondé Vassalo. Petrópolis, RJ: Vozes, 1977.

GEERTZ, Clifford. The Interpretation of Cultures: Selected Essays. New York: Basic Books, 1973.

GOFFMAN, Erving. Estigma: notas sobre a manipulação da identidade deteriorada. LTC: Rio de Janeiro, 1981.

GONÇALVES, Carolina. Ministério da Saúde confirma a relação entre vírus zika e microcefalia. Agência Brasil, 2015. Acesso em 30/07/2019:http://agenciabrasil.ebc.com.br/geral/noticia/2015-11/ministerio-da-saude-confirma-relacao-entre-virus-zica-e-microcefalia

JAMES, Alisson; PROUT, Alan. Constructing and reconstructing childhood: Contemporary issues in the sociological study of childhood. London: Falmer Press, 1990.

KITTAY, Eva. The Ethics of Care, Dependence, and Disability. Ratio Juris, 24 (1): 49-58, 2011

KRÖEBER, Alfred. "O superorgânico”. In: A Natureza da Cultura. Lisboa: Edições 70, 1933. pp. 39-79.

LANDSMAN, Gail. Reconstructing Motherhood and Disability in the Age of Perfect Babies. London: Routledge, 2008.

LAYNE, Linda. "How's the baby doing?": Struggling with narratives of progress in a neonatal intensive care unit. Medical Anthropology Quarterly, 10 (4): 624656, 1996.

LE BRETON, David. Adeus ao corpo: antropologia e sociedade. Campinas: Papirus, 2003.

LEITE JR, Jorge. Monstros, bufões e freaks: riso, medo e a exclusão dos anormais. Revista Boca Larga, Caderno dos Doutores da Alegria, 2, 2006.

LIRA, Luciana C.; SCOTT, Russel Parry; SOUZA, F. M. Trocas, Gênero, Assimetrias e Alinhamentos: experiência etnográfica com mães e crianças com síndrome congênita do Zika. Revista Anthropológicas, 28 (2): 206-237, 2017.

LIRA, Lays. Mães de micro: três redes de cuidado e apoio no contexto do surto da síndrome congênita do vírus zika no Recife (PE). Monografia. Departamento de Antropologia da Universidade de Brasília, 2017. 
MACHADO, Lia Zanotta. Interfaces e deslocamentos: feminismos, direitos, sexualidades e antropologia. Cadernos Pagu, 42: 13-46, 2014.

MAUSS, Marcel. “As técnicas corporais”. In: Sociologia e antropologia. São Paulo: CosacNaify, 2003.

MELLO, Anahi; NUERNBERG, Adriano. Gênero e deficiência: interseções e perspectivas. Estudos Feministas, 20 (3): 635-655, 2012.

MELLO, Anahi. Por uma abordagem antropológica da deficiência: pessoa, corpo e subjetividade. Monografia (graduação em Ciências Sociais), Universidade Federal de Santa Catarina, Centro de Filosofia e Ciências Humanas, 2009.

MENDONÇA, João Martinho. Margaret Mead, Bali e o Atlas do comportamento infantil. Horizontes Antropológicos, 16 (34): 315-348, 2010.

MOL, Annemarie. "Política ontológica: algumas ideias e várias perguntas”. In: Objectos impuros: experiências em estudos sociais da ciência. Porto: Edições Afrontamento, 2008.

MOSER, Ingunn. Against normalisation: subverting norms of ability and disability. Science as Culture, 9 (2): 201-240, 2000.

OLIVER, Michael. Understanding Disability: From Theory to Practice. Basingstoke/New York: Palgrave, 1996.

PORTO, Rozeli. "Saúde, contracepção e aborto: profissionais de saúde e suas relações com mulheres usuárias do SUS no RN”. In: Antropologia e mediadores no campo das políticas de saúde, Brasília, 2014.

RAPP, Rayna; FAYE, Ginsburg. Enabling Disability: Rewriting Kinship, Reimagining Citizenship. Public Culture, 13 (3): 533-556, 2001.

SCHUTZ, Alfred. “On Multiple Realities”. In: NATANSON, Maurice (ed.). Collected Papers, vol. I: The Problem of Social Reality. The Hague: Nijhoff, [1945] 1962. pp. 207-59.

SIEBERS, Tobin. Disability Theory. Ann Arbor: University of Michigan Press, 2008.

STENGERS, Isabelle. Introductory notes on an ecology of practices. Cultural Studies Review, 11 (1), 183-196, 2005.

THELEN, Esther. Motor development: A new synthesis. American Psychologist, 50 (2): 79-95, 1995.

THELEN, Esther. Development as a dynamic system. Current Directions in Psychological Science, 1 (6): 189-193, 1992.

VALIM, Thais. Interpretando cuidados: narrativas maternas acerca do desenvolvimento de bebês nascidos com a Síndrome Congênita do Zika Vírus em Recife/PE. Áltera, 1 (8): 94-114, 2019.

WERNECK, Cláudia. Manual sobre Desenvolvimento Inclusivo para a Mídia e Profissionais de Comunicação. Rio de Janeiro: WVA Editora, 2004.

WILLIAMSON, Eliza. Cuidado nos tempos de Zika: notas da pós-epidemia em Salvador (Bahia), Brasil. Interface, 22 (66): 685-696, 2018. 